\title{
A REPORT OF CENTRAL RETINAL ARTERY OCCLUSION (CRAO), IN YOUNG MALES IN ITS INITIAL MANIFESTATION, AS PRIMARY ANTIPHOSPHOLIPID SYNDROME.
}

Rani Sujatha, Huda Farooq Tonse.

\author{
1. Professor \& Head of the Department. Department of Ophthalmology, Dr. B. R. Ambedkar Medical College \& \\ Hospital. \\ 2. Post Graduate. Department of Ophthalmology, Dr. B. R. Ambedkar Medical College \& Hospital.
}

\section{CORRESPONDING AUTHOR:}

Dr. Rani Sujatha,

\#236,7th Cross, 1 st Stage,

Indira Nagar, Bangalore.

E-mail: drranisujatha@gmail.com

ABSTRACT: AIM: To report a case of Central Retinal Artery Occlusion (CRAO) in young males in its initial manifestation as Primary Antiphospholipid Syndrome. METHODS: 32 year healthy male, with abrupt sudden painless loss of vision in right eye since 48 hours, with Grade 2 Relative afferent pupillary defect, visual acuity of hand movements in OD and 6/18 in OS. Fundoscopy disclosed signs compatible of central retinal artery occlusion confirmed with FFA. Carotid Doppler imaging and echocardiography was done to determine the source. RESULTS: Antiphospholipid antibody cofactor, beta2-glycoprotein 1 antibodies, IgM, was positive with titre of more than 94 un its/ml on two occasions, 12 weeks apart, with normal range being less than 20 units/ml for each isotope (IgG, IgM, or IgA).According to the 2006 revised Sapporo criteria Antiphospholipid syndrome was diagnosed. Thorough examination excluded other system involvement. Immunological studies excluded other systemic disorders. CONCLUSIONS: In literature, prevalence of CRAO is $0.85 \%$ for every 100000 and prevalence of Antiphospholipid Syndrome in patients showing a major retinal vascular obstruction is $5 \%-33 \%$. Antiphospholipid syndrome should be ruled out in every young patient who presents with Central retinal artery occlusion. Association must be considered, as Central retinal artery occlusion could be the initial manifestation of antiphospholipid syndrome with high risk of recurrence.

INTRODUCTION: Von Graefe in 1859 first described case of Central Retinal artery occlusion caused by multiple systemic emboli from endocarditis.1; 2Central retinal artery occlusion constitutes $57 \%$ of acute retinal occlusion 3 .

Retinal Artery Occlusion is uncommon in the young population. An estimated 0.85 per 10,000 patients over the age of 40 years are affected 4, 5, and 6. Information regarding risk factors in younger age group is scanty. Hyperhomocysteinemia is the commonest association Retinal Artery Occlusion in the young Indian population 7.

In Patients with antiphospholipid syndrome the frequency of occulo vaso-occlusive disorders ranges $0.5 \%$ to $8 \%$ with majority affecting retinal vasculature8, 9, 10, and 11 . Antiphospholipid syndrome is characterized by the production of moderate to high levels of antiphospholipid antibodies, associated with thrombotic phenomena.12 
Antiphospholipid syndrome occurs most commonly in patients with other underlying autoimmune diseases. If these antibodies are present in the absence of another recognizable autoimmune disease, the syndrome is known as primary antiphospholipid syndrome (PAS).12

Ocular manifestation of primary antiphospholipid syndrome is transient visual disturbances, although most of them are related to central nervous system rather than ocular ischemia. Ocular involvement is uncommon 13. Occlusion of central retinal artery and vein is the most common finding in secondary APS, antiphospholipid syndrome associated with other underlying autoimmune disease. 14

Castanon et al reported a high prevalence of ocular disease in patients with primary antiphospholipid syndrome, with $88 \%$ of patients (15 out of 17 patients) demonstrating fundoscopic abnormalities, and only $29 \%$ of patients having vaso-occlusive retinopathy 15.Studies are missing on the frequency and clinical presentation of the ocular manifestations as the initial first sign of antiphospholipid syndrome. We present a case of central retinal artery occlusion in a young male as its initial presentation in primary antiphospholipid syndrome

CASE REPORT: 32 year healthy male presented with abrupt painless loss of vision in right eye since 48 hours, with Grade 2 RAPD, visual acuity of hand movements in OD and 6/18 in OS. On fundoscopy, right eye pale retina with cherry red spot. On FFA right eye, normal choroid filling with delay in arterial filling, with leading edge of dye visible in arteries with the left eye FFA normal.

\section{LABORATORY INVESTIGATIONS}

Homocysteine level - 16.37[normalvaule-6.3-11.2mmol/l), C.R.P was negative. Prothrombin time was - 16.6 controls - 14, ratio - 1.15, INR - 1.17 .

Extended Antiphospholipid antibodies profile showed: B2 glycoprotein IgM strongly positive with value of $93[\mathrm{~N}<20]$ (two occasions 12 weeks apart). Anticardiolipin/anti lupus was negative. APTT/PT= normal. C3 and C4- were within normal limits. Negative for HBC, HBsAg, VDRL, p-ANCA/c-ANCA and HIV1\&2 Non reactive.

Electroneuromyography studies showed: Right side predominant ulnar nerve involvement, with right radial nerve, medial nerve, and left superficial peroneal nerve in Lower limb suggestive of mononeuritis multiplex.

Nerve biopsy: Right radial nerve - shows sparse perivascular inflammatory changes, axonal type of nerve involvement.

Hb \% -12.3, RBC - 4.92cells/mm3, WBC - 7.9 cells /mm3, Platelet Count - 235 cells $/ \mathrm{mm} 3$, HCT 35.8,ESR $-52 \mathrm{~mm} / \mathrm{hr}$,RBS $-100 \mathrm{mg} / \mathrm{dl}$. Peripheral smear reports: Normocytic hypochromic anaemia. Urine routine, renal function test, liver function test and electrolytes were normal. Carotid \& vertebral Doppler, USG abdomen, ECG \& Chest X-Ray was normal. ECHO revealed: Grade 1 MVP

RESULTS: Central Retinal Artery Occlusion right eye secondary to primary antiphospholipid syndrome with high titres anti-beta-2-glycoprotein I antibodies

DISCUSSION: The ophthalmic artery is the first branch of the internal carotid artery and enters the orbit underneath the optic nerve through the optic canal. The central retinal artery is the first intra orbital branch of the ophthalmic artery, which enters the optic nerve 8-15 $\mathrm{mm}$ behind 


\section{CASE REPORT}

the globe to supply the retina. Short posterior ciliary arteries branch distally from the ophthalmic artery and supply the choroid.

APS is largely seen in young women with female to male ratio of 3.5:1.

In antiphospholipid syndrome incidence of CRAO- 7\%.Ocular manifestations in primary antiphospholipid syndrome have a low prevalence with a tendency to be more affected in the Secondary APS. The frequency of ocular vaso-occlusive disorders in patients with this syndrome ranges from 0.5 to $8 \%$, with the majority affecting the retinal vasculature.

Revised Sapparo Criteria:

CLINICAL: Vascular thrombosis: Arterial, venous, or small vessel, in any tissue or organ, confirmed by objective validated criteria.

Pregnancy morbidity: Unexplained fetal death at or beyond 10 weeks gestation. Premature birth before 34 weeks gestation due to eclampsia, or severe pre-eclampsia, or placental insufficiency, three or more consecutive spontaneous abortions before 10 weeks gestation.

LABORATORY: Lupus anticoagulant, present on at least 2 occasions, at least 12 weeks apart. Anticardiolipin antibodies (ACA), IgG or IgM $>30$ units for both, present on at least 2 occasions, at least 12 weeks apart.

Anti-beta-2-glycoprotein I antibodies (anti-B2GPI), IgG or $\operatorname{Ig} M>20$ units for both, present on at least 2 occasions, at least 12 wks apart.

The presence of isolated ocular thrombosis with persistently increased titers of antiphospholipid antibodies should be considered as definite APS. The treatment of isolated ocular APS should be based on the same principles as in all patients with systemic APS 16.The survival rate of catastrophic APS is about $50 \%$, but the long term outcome of patients who survive is unknown 17. However In young patients without any conventional risk factors, with retinal vascular occlusion screening for antiphospholipid is important 18. Antiphospholipid syndrome must be studied in cases of severe retinal vascular occlusion in young patients. Its diagnosis is important because the risk of recurrent thrombotic events may endanger functional and vital prognosis 19.

CONCLUSION: Screening for APS is important in young patients with retinal vascular occlusion, especially in those without conventional risk factors. Early diagnosis and treatment of antiphospholipid syndrome can prevent extension of thrombus to other vessel in body and thereby reduce mortality. Central artery occlusion in young male should raise suspicion of antiphospholipid syndrome .Management of these patients involve a team-approach with a haematologist/oncologist or rheumatologist to manage the coagulation status of these patients to prevent further systemic vascular occlusions.

\section{REFERENCES:}

1. Von graefe A .Ueber Embolie der Arteria centralis retinae als Ursache plotzlicher Erblindung.Albrecht von Graefes Arch Ophthalmol 1859;5:136-57

2. Sohan Singh Hayreh,Retinal Artery Occlusion ,Associated Systemic and Ophthalmic Abnormalities.Amercian Academy of Ophthalmology ,2009;116:8-10

3. Brown GC,Reber R. An Unusual presentation of branch retinal artery occlusion with ocular neovascularization.Can J Ophthalmol 1986; 21:103-6. 
4. Rumelt S, Dorenboim Y, Rehany U. Aggressive systematic treatment for central retinal artery occlusion. Am J Ophthalmol 1999; 128:733-8?

5. Brown GC, Magargal LE, Shields JA, Goldberg RE, Walsh PN. Retinal arterial obstruction in children and young adults. Ophthalmology 1981; 88:18-25.

6. Greven CM, Slusher MM, Weaver RG. Retinal arterial occlusion in young adults. Am J Ophthalmol 1995; 120:776-83?

7. Dhanashree Ratra, Maneesh Dhupper, Retinal arterial occlusions in the young: Systemic associations in Indian population, Indian Journal Of Ophthalmology, Year : 2012 | Volume : 60 | Issue : 2 | Page : 95-100

8. Demirci FY, Kucukkaya R, Akarcay K, Kir N, Atamer T, Demirci H et al. Ocular involvement in primary antiphospholipid syndrome. Int Ophthalmol 1999; 22(6): 323329.

9. Castanon C, Amigo MC, Banales JL, Nava A, Reyes PA. Ocular vaso-occlusive disease in primary antiphospholipid syndrome. Ophthalmology 1995; 102(2): 256-262.

10. Wiechens B, Schroder JO, Potzsch B, Rochels R. Primary antiphospholipid antibody syndrome and retinal occlusive vasculopathy. Am J Ophthalmol 1997; 123(6): 848-850.

11. Boets EP, Chaar CG, Roday K, Keunen JE, Breedveld FC. Chorioretinopathy in primary antiphospholipid syndrome: a case report. Retina 1998; 18(4): 382-385.

12. Asherson RA. A "primary" antiphospholipid syndrome.J Rheumatol 1988;15:1742-6

13. Y A Gelfand, D Dori, B Miller, B Brenner. Visual disturbances and pathologic ocular findings in primary antiphospholipid syndrome. Ophthalmology. 1999 Aug ;106 (8):1537-40 10442901 Cit:5

14. Suvajac G, Stojanovich L, Milenkovich S. Ocular manifestations in antiphospholipid syndrome Autoimmun Rev. 2007 Jun;6(6):409-14. Epub 2006 Dec 20.

15. L Pek-Kiang Ang1, A Tock-Han LIM2 and E-Y Yap2. Central retinal vein and ophthalmic artery occlusion in primary antiphospholipid syndrome,Letter to the Journal. Eye (2004) 18, 439-440. doi:10.1038/sj.eye.6700685

16. D. Yehudai, Y. Shoenfeld, E. Toubi . Looking Into the Eyes of Patients with Antiphospholipid Syndrome. Clinical Reviews in Allergy \& Immunology April 2007, Volume 32, Issue 2, pp 192-197

17. D Erkan1, R A Asherson2, G Espinosa3, R Cervera3, J Font3, J-C Piette4, M D Lockshin1, for the Catastrophic Antiphospholipid Syndrome Registry Project Group. Long term outcome of catastrophic antiphospholipid syndrome survivors Ann Rheum Dis 2003;62:530-533 doi:10.1136/ard.62.6.530

18. Demirci FY, Küçükkaya R, Akarçay K, Kir N, Atamer T, Demirci H, Ongör E. Ocular involvement in primary antiphospholipid syndrome. Ocular involvement in primary APS, Int Ophthalmol. 1998; 22(6):323-9.

19. Trojet S, Loukil I, El Afrit MA, Mazlout H, Bousema F, Rokbani L, Kraiem A. Bilateral retinal vascular occlusion during antiphospholipid antibody syndrome: a case report. J Fr Ophtalmol. 2005 May;28(5):503-7

20. Behbehani R, Sergott RC, Savino PJ. The antiphospholipid antibody syndrome: diagnostic aspects. Curr Opin Ophthalmol. 2004 Dec; 15(6):483-5. 


\section{CASE REPORT}

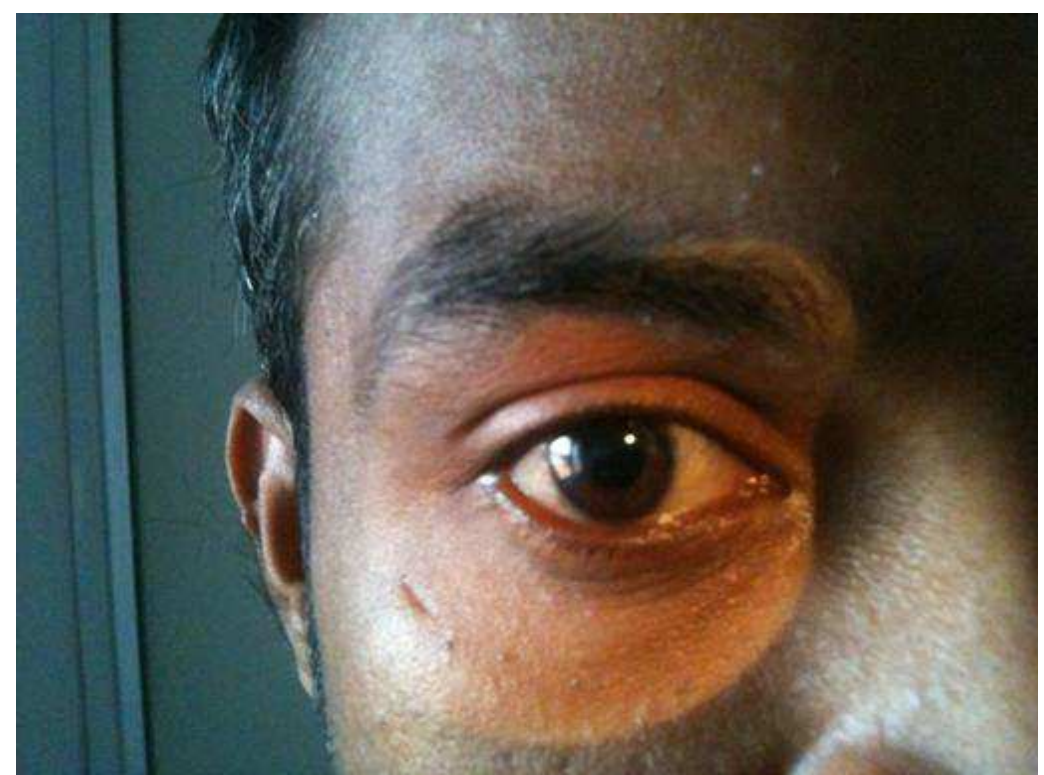

FIGURE 1: young male with painless loss vision \& grade 2 RAPD right eyes

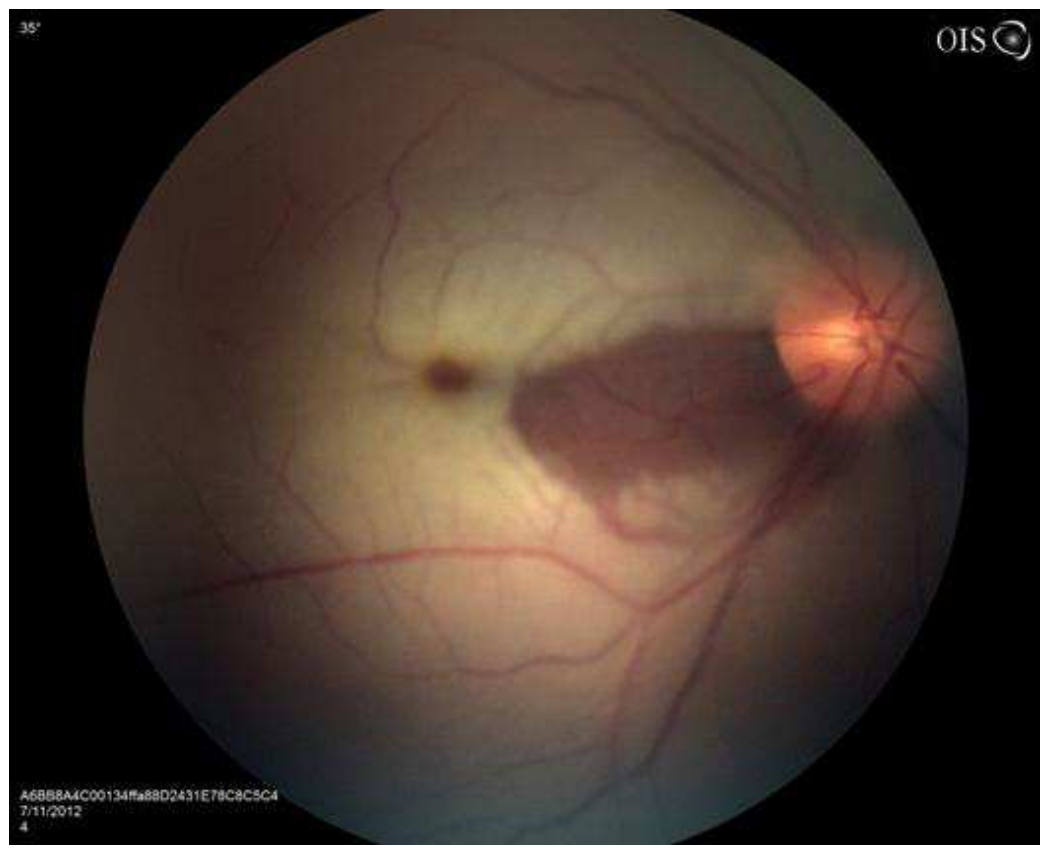

FIGURE 2: Right eye fundus showing central retinal artery occlusion with cherry red spot 


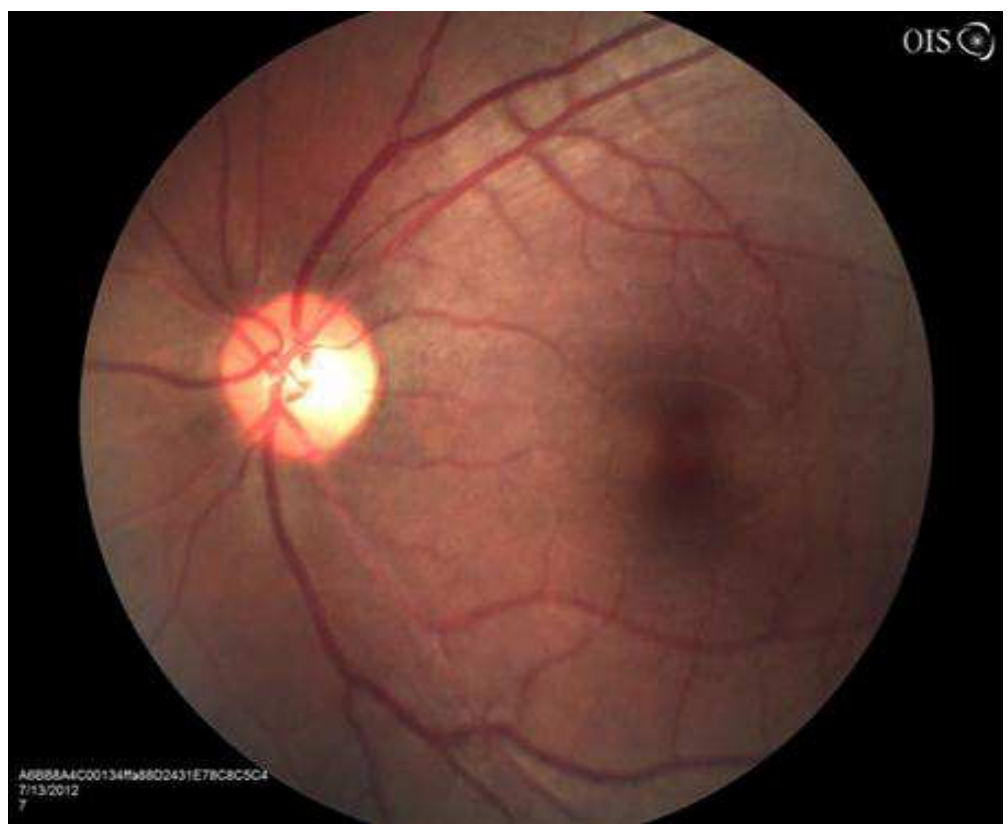

FIGURE 3: Left eye fundus normal

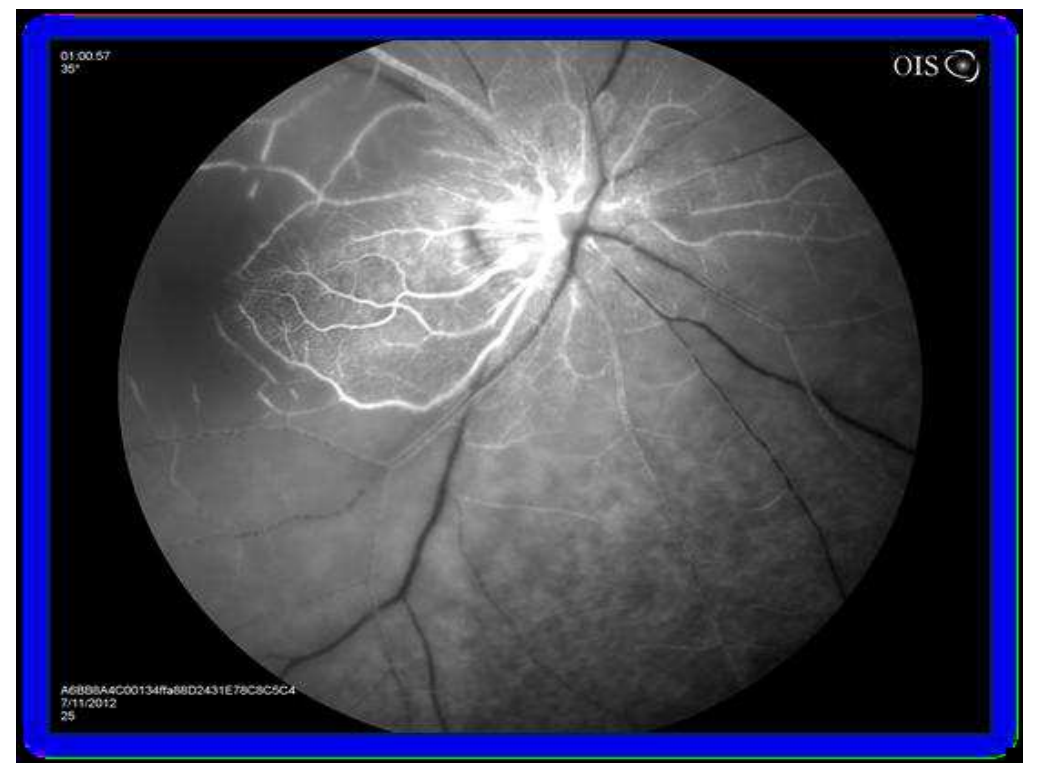

FIGURE 4: Right eye FFA showing Delayed arterial filling (1.00 minute) Leading edge of dye visible in the retinal arteries 


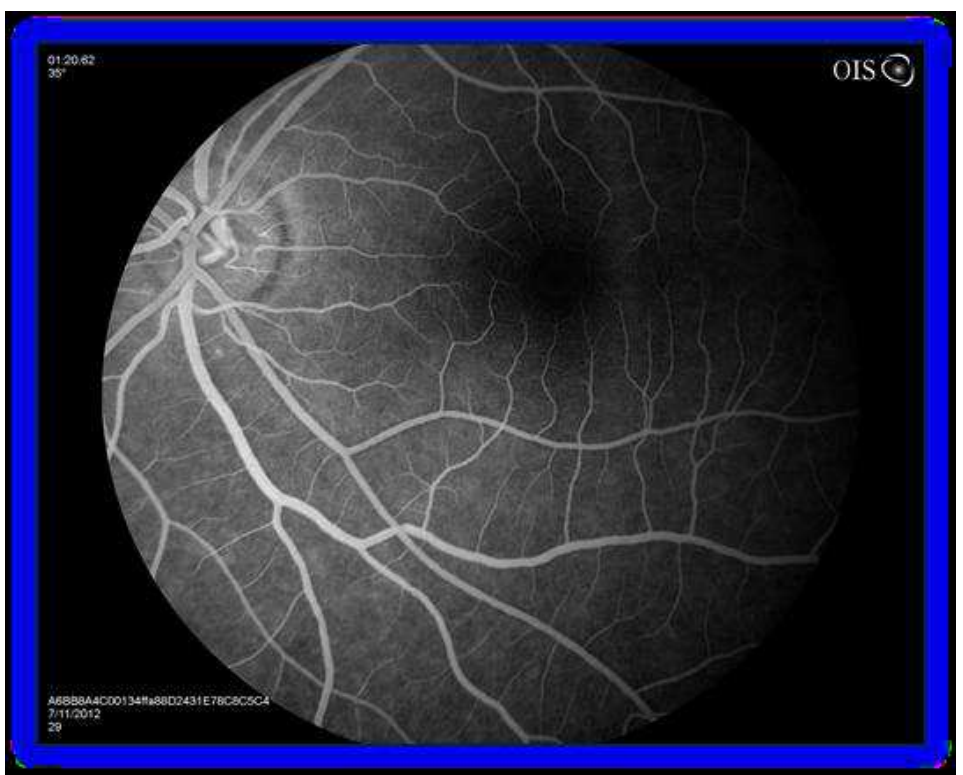

FIGURE 5: left eye FFA normal

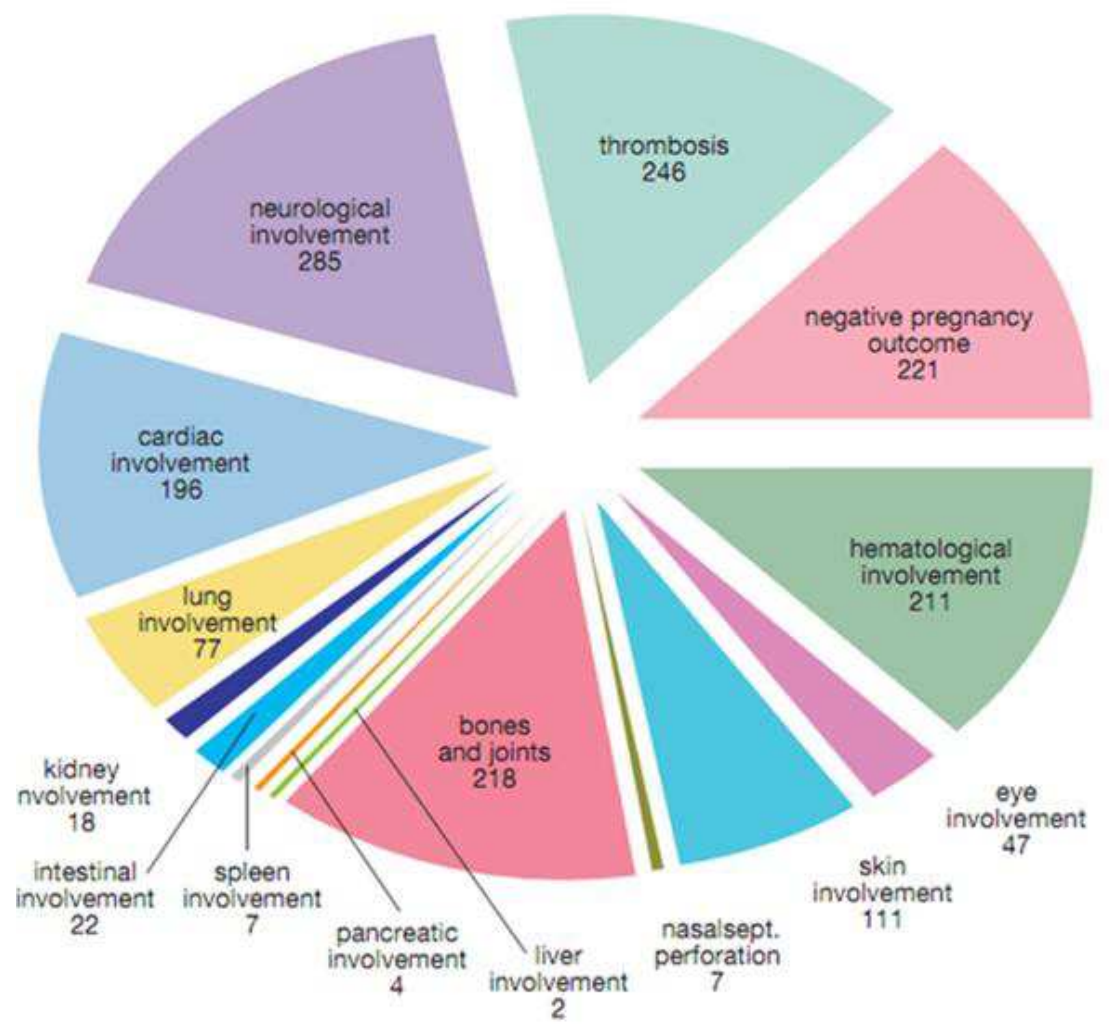

FIGURE 6 : Eye involvement in antiphospholipid syndrome 47 per 1000 cases. 